\title{
Partially trombosed glomus type spinal arteriovenous malformation - case presentation
}

\author{
M.R. Gorgan, Narcisa Bucur, Catioara Cristescu, A. Giovani
}

\begin{abstract}
Spinal AVM are very rare vascular lesions and most o the studies give reports on only a few cases. Given their localization between the spinal tracts and the gray matter core of the medulla and their multiple feeders from posterior and anterior spinal arteries they are amongst the most difficult surgical pathology in the nervous sistem. We present the case of a 60 years old male with a glomus type T10-L2 spinal AVM that presented with motor deficit in the lower limbs and urinary incontinence. The partially thrombosed lesion was completely resected without previous embolisation, and the patient was walking with assistance at discharge. This is a rare case that presented with progressive neurological deterioration consistent with an ischemic rather than a hemorrhagic event. Microsurgery is a better option than conservative treatment in these rare cases of spontaneous occlusion of intramedullary arteriovenous malformations.
\end{abstract}

Key words: arteriovenous malformation, spinal cord ischemia.

\section{Introduction}

Only $4 \%$ of primary intraspinal masses are AVM's, and most of the publications include reports on a small number of cases. Lawton et al. analised one of the most comrehensive series of 304 pacients trated with AVM resection over a period of 7,8 years and concluded that $25 \%$ of the patients presented diffuse niduses and $18 \%$ had deep perforating artery supply. These lesions are most common in the adult age. $(15,23)$

Eighty-five percent of spinal AVMs involve progressive neurological symptoms over months to years, especially back pain associated with progressive sensory loss and lower extremity weakness. Ten percent to 20 percent involve a sudden onset of weakness, numbness, difficulty urinating, urinary incontinence, fecal incontinence, or paralysis (usually in patients younger than 30 ) as a result of hemorrhage. $(20,21,24)$

Many classifications have been proposed for arteriovenous fistulas and arteriovenous malformation. Spetzler et all proposed the most complete classification for spinal arteriovenous lesions recognizing 3 types of arteriovenous fistulas namely dorsal intradural, ventral intradural and extradural and 3 types of arteriovenous malformations namely intramedullary, extra-intradural, and conus. Intramedullary AVM's are also called 
type II spinal AVM's, glomus type lesions or angioma racemosum arteriovenosum. $(26,27)$ As most of these lesions are treated either by embolisation or microsurgery when they are discovered, there is little data available on the natural history of these AVM's. $(2,5)$ Usually this high flow lesions are supplied from a few arterial sources from anterior and posterior spinal arteries and drain into the coronal venous plexus. The veins are in most cases tortuous and dilated. (12, 13, 25) The neurological deficit that brings the patient to the hospital can be caused either by hemorrhage resulting from the AVM rupture mass effect vascular steal or ischemia related to venous thrombosis of the malformation. We present a rare case of spontaneously occluded intramedullary AVM.

\section{Case presentation}

A 60 years old man presented with a slowly progressive neurological deficit over several months. The neurological exam showed grade $2 / 5$ motor deficit in the right lower limb and $3 / 5$ motor deficit in the left lower limb and urinary incontinence. He was known with hepatitis B virus infection and an L1 fracture with anterior L1/L2 dislocation after a vertebral trauma 24 years before. At that time (1989) the dislocation was reduced and anteriorly fixated.

Spinal MR imaging showed a T11-L1 intramedullary lesion suggestive for arteriovenous malformation. There was no evidence of spinal cord hemorrhage. Unfortunately the angiography was not available. The surgery was performed via a posterior approach, using multilevel laminectomies extending one level above and one level below the AVM nidus.
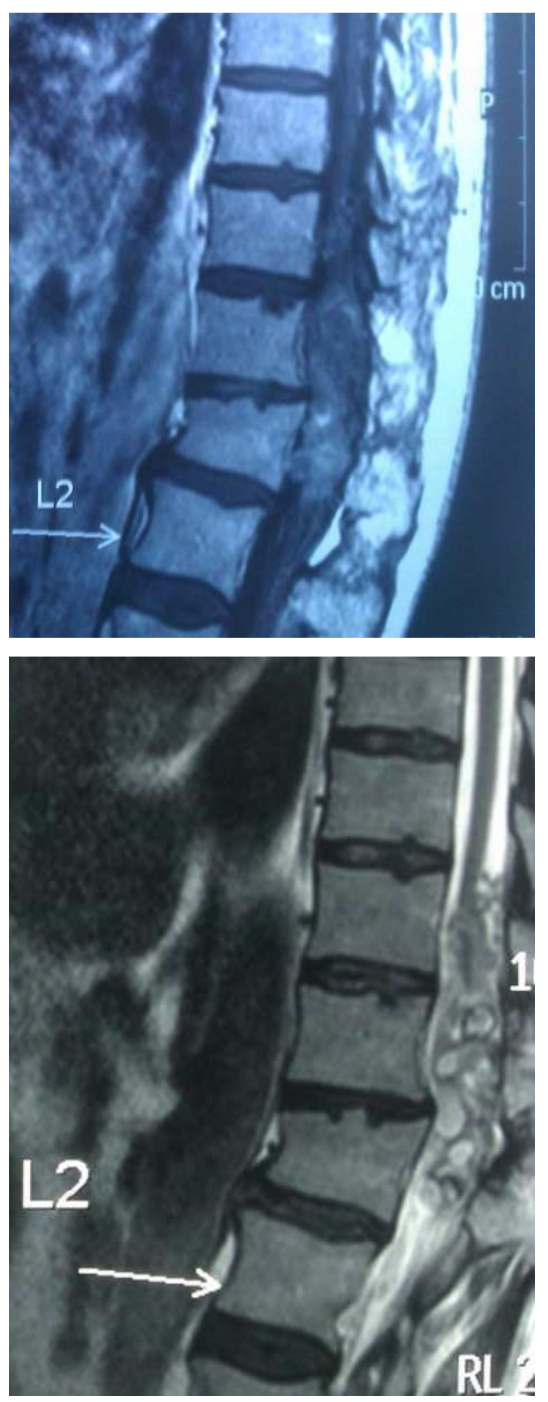

Figure 1 - T1 and T2 sagital MR image of a intramedullary lesion 
DOI: 10.2478/romneu-2014-0060
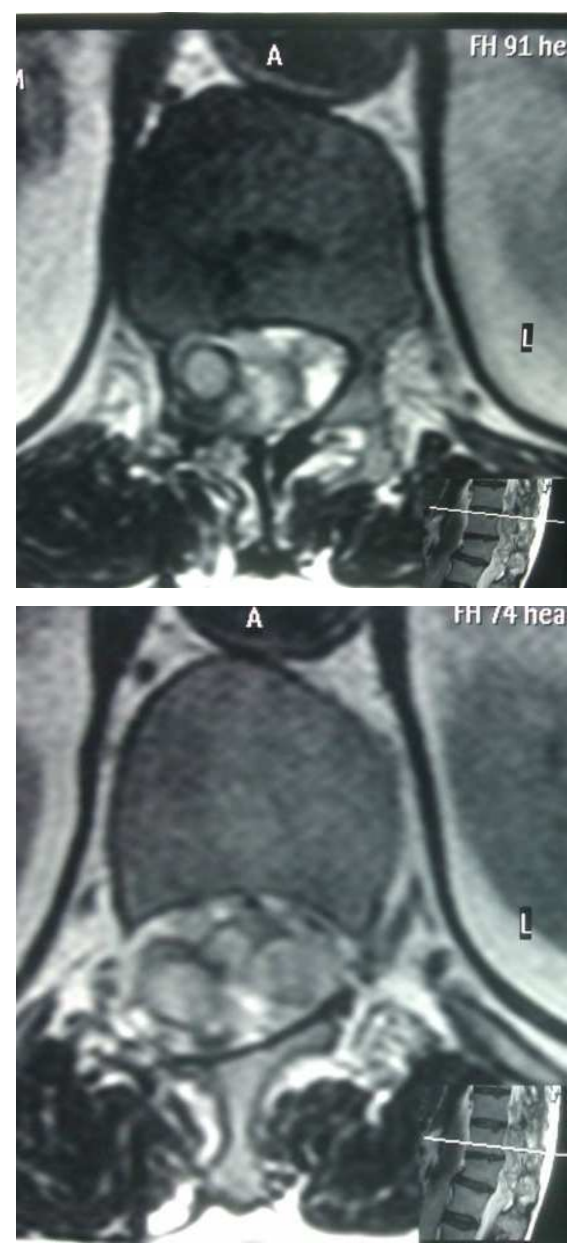

Figure 2 - Axial MRI through the intramedullary lesion showing the tangled thrombosed vessels

The dura was opened through a midline incision from $\mathrm{T} 10$ to $\mathrm{L} 2$ given the posterior location of the lesion and suspended to the musculature. Two large nests of tangled draining veins, one at T11 and one at L1, connected by a large tortuous vein were observed on the surface of the medulla. By carefully inspecting the lesion we observed that the nidus extended from the parenchyma into the extrapial space. Using an intrapial technique we mobilized the tortuous veins and we observed no change in the colour of the veins by sqeezing them berween the bipolar forceps, this being the test of them being thrombosed. Than the nidus was shrinked using the bipolar at the lowest and the extrapial portion of the AVM was completely resected. Even The intraparenchymal portion of the nidus was left intact in order to avoid supplementary lesions to the medulla as the AVM has been devascularised. An arterial source from the Adamkiewicz artery is clipped and coagulated, leaving the artery pulsatile. Before closure of the dura, the pale medulla regains a normal vascular design.

In the first few days postoperative, the neurological deficit improved to a motor deficit of 3/5 in the right leg and 4/5 in the left leg. The pacient was discharged one week after surgery when he was able to walk with support.

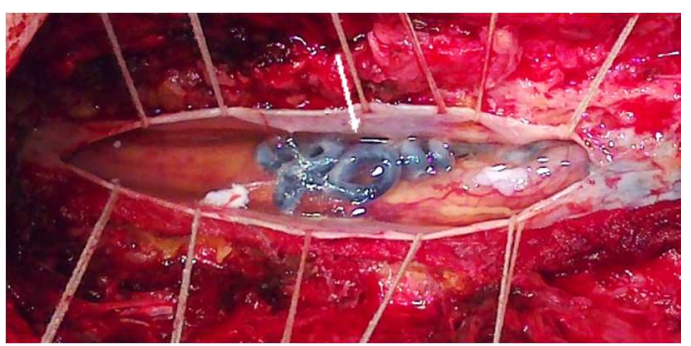

Figure $3 \mathrm{~A}$ - superior nest of extrapial nidus

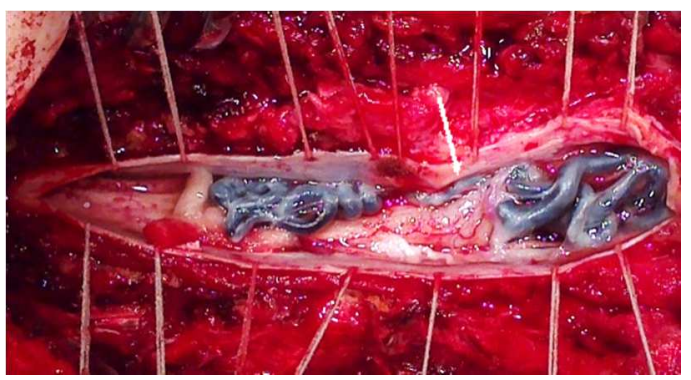

Figure $3 \mathrm{~B}$ - superior and inferior parts of the extrapial nidus united by a dilated vein on the right side of the medulla (arrow) 


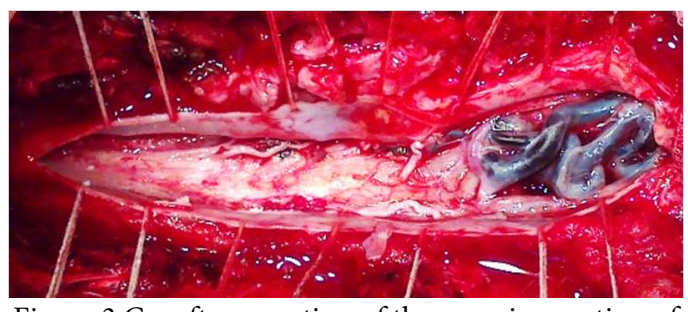

Figure $3 \mathrm{C}$ - after resection of the superior portion of the nidus

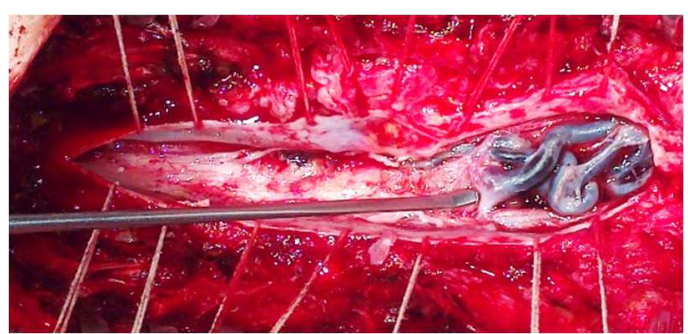

Figure $3 \mathrm{D}$ - the dissector is pointing to the artery feeding the nidus

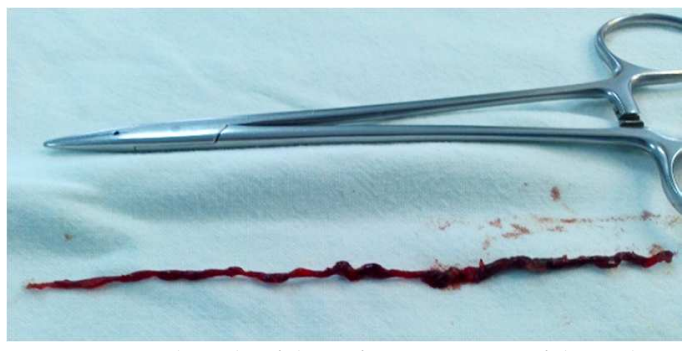

Figure $3 \mathrm{E}$ - length of the inferior portion of the nidus

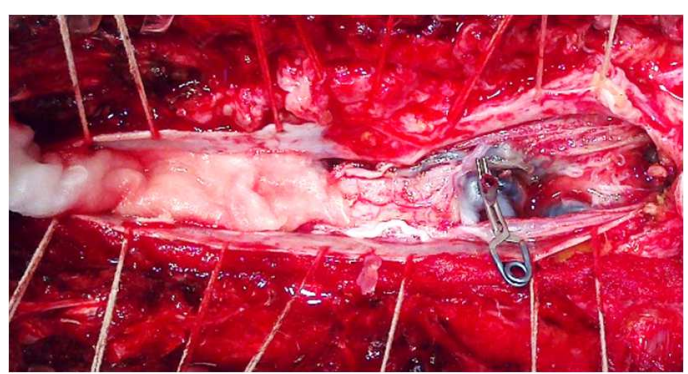

Figure $3 \mathrm{~F}$ - clip on the vein of the AVM that goes to the intrapial nidus

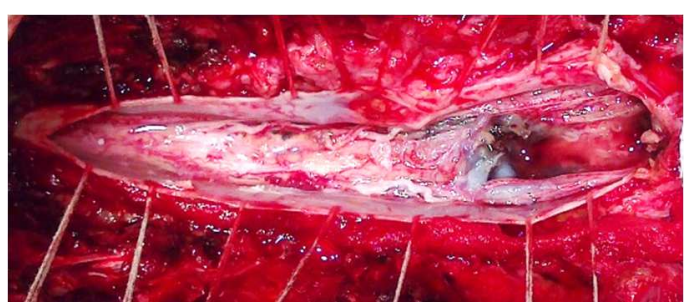

Figure $3 \mathrm{G}$ - final aspect after coagulation of the venous drainage

\section{Discussion}

The progressive exacerbation-remission neurological deficit suggests an ischemic rather than a hemorrhagic sufferance of the medulla. As the blood supply of the spinal cord comes from radicular arteries, two watershed areas can be defined, one between cervicothoracic and midthoracic area and one between midthoracic and thoracolumbar area that are devoid of radicular arteries. This anatomical fact predisposes these regions to ischemic injury. As hypoxia leads to the release of several cytokines that affect the local angioarchitecture it is easy to suppose that an AVM present at birth goes through a series of vascular remodeling and in time the venous drainage becomes impaired. From the vascular rearrangement standpoint the fate of any spinal AVM is either thrombosis or bleeding secondarily to proteolitic wall dissection. $(3,4)$ The blood flow in this high flux lesions has two direct consequences leading to hipoxia, first of all the vascular steal, preventing arterialized blood to reach the capillaries and the turbulence that is recognized as a prothrombotic factor. Both of these promote venous outflow obstruction, leading to stasis and thrombosis. $(17,18,19)$ 
DOI: 10.2478/romneu-2014-0060

Two approaches have been used to resect intramedullary AVM's, one is going for the arterial supply first and sacrificing the draining veins as the final act of the resection, as described by Spetzler as the pial resection technique and the other preferred by most of the other authors goes to resecting the venous elements at the beginning. We only completed the resection of the extrapial nidus after coagulating the main arterial afferent coming from the Adamkiewicz artery. $(6,7)$

We found only three cases of spontaneous occlusion of an intramedullary AVM in the literature, demonstrated on angiography but none of them was microsurgically explored. (1)

Even if there is no direct relationship between the vertebral trauma the patient suffered 24 years earlier and his intramedullary malformation, we can speculate that the trauma, by modifying the local blood flow and inducing a grade of hypoxia, stimulated remodeling of the malformation's venous system and contributed to the growth of the nidus as to aquire this three metameres length and ultimately to the venous thrombosis. $(8,9,10)$

\section{Conclusion}

Spinal AVM's are very complex vascular lesions and the first line of treatment is endovascular. There are cases where endovascular treatment cannot be employed and microsurgery comes into play. It is not advisable though to go for a complete occlusion given the high risk of disastrous consequences. Considering the good outcome of the surgery it appears that microsurgery is a better option than conservative treatment in these rare cases of spontaneous occlusion of intramedullary arteriovenous malformations.

\section{Correspondence}

Giovani Andrei

giovani.andrei@gmail.com

\section{References}

1. Chun JY, Gulati M, Halbach V, Lawton MT: Thrombosis of a spinal arteriovenous malformation after hemorrhage: case report. Surg Neurol 61:92-94, 2004 2. Connolly ES Jr, Zubay GP, McCormick PC, Stein BM: The posterior approach to a series of glomus (Type II) intramedullary spinal cord arteriovenous malformations. Neurosurgery 42:774-776, 1998

3. Corkill RA, Mitsos AP, Molyneux AJ: Embolization of spinal intramedullary arteriovenous malformations using the liquid embolic agent, Onyx: a single-center experience in a series of 17 patients. J Neurosurg Spine 7:478-485, 2007

4. Djindjian R, Cophignon J, Rey A, Theron J, Merland JJ, Houdart R: Superselective arteriographic embolization by the femoral route in neuroradiology. Study of 50 cases. II. Embolization in vertebromedullary pathology. Neuroradiology 6: 132-142, 1973

5. Doppman JL, Di Chiro G, Dwyer AJ, Frank JL, Oldfield EH: Magnetic resonance imaging of spinal arteriovenous malformations. J Neurosurg 66:830-834, 1987

6. Felner EI, Goto CS: Acute flank pain: an unusual presentation of a spinal AVM. Am J Emerg Med 17:382384, 1999

7. Ferch RD, Morgan MK, Sears WR: Spinal arteriovenous malformations: a review with case illustrations. J Clin Neurosci 8:299-304, 2001

8. Frisbie JH: Spinal cord lesions caused by arteriovenous malformation: clinical course and risk of cancer. J Spinal Cord Med 25:284-288, 2002

9. Gilsbach JM: Treatment options in spinal nidus-type plexiform AVMS. Surgery. Riv Neuroradiol 17:383-388, 2004

10. Hida K, Shirato H, Isu T, Seki T, Onimaru R, Aoyama $\mathrm{H}$, et al: Focal fractionated radiotherapy for intramedullary spinal arteriovenous malformations: 10year experience. J Neurosurg 99:34-38, 2003

11. Horton JA, Latchaw RE, Gold LH, Pang D: Embolization of intramedullary arteriovenous malformations of the spinal cord. AJNR Am J Neuroradiol 7:113-118, 1986

12. Ito M, Yamamoto T, Mishina H, Sonokawa T, Sato K: 
Arteriovenous malformation of the medulla oblongata supplied by the anterior spinal artery in a child: treatment by microsurgical obliteration of the feeding artery. Pediatr Neurosurg 33:293-297, 2000

13. Kuga T, Esato K, Zempo N, Fujioka K, Harada M, Furutani A, et al: Successful management of a giant spinal arteriovenous malformation with multiple communications between primitive arterial and venous structures by embolization: report of a case. Surg Today 26:756-759, 1996

14. Lasjaunias P, Rodesch G, Alvarez H: Treatment options in spinal AVMS. Endovascular approach with NBCA. Riv Neuroradiol 17:375-376, 2004

15. Lundqvist C, Andersen O, Blomstrand C, Svendsen P, Sullivan M: Spinal arteriovenous malformations. Healthrelated quality of life after embolization. Acta Neurol Scand 90:337-344, 1994

16. McCormick PC, Torres R, Post KD, Stein BM: Intramedullary ependymoma of the spinal cord. J Neurosurg 72:523-532, 1990

17. Meisel HJ, Lasjaunias P, Brock M: Modern management of spinal and spinal cord vascular lesions. Minim Invasive Neurosurg 38:138-145, 1995

18. Menku A, Akdemir H, Durak AC, Oktem IS: Successful surgical excision of juvenile-type spinal arteriovenous malformation in two stages following partial embolization. MinimInvasive Neurosurg 48:5762, 2005

19. Morgan MK: Outcome from treatment for spinal arteriovenous malformation. Neurosurg Clin N Am
10:113-119, 1999

20. Newton TH, Adams JE: Angiographic demonstration and nonsurgical embolization of spinal cord angioma. Radiology 91:873-876, passim, 1968

21. Niimi Y, Berenstein A, Setton A, Neophytides A: Embolization of spinal dural arteriovenous fistulae: results and followup. Neurosurgery 40:675-683, 1997 22. Ohata K, Takami T, Gotou T, El-Bahy K, Morino M, Maeda M, et al: Surgical outcome of intramedullary spinal cord ependymoma. Acta Neurochir (Wien) 141:341 347, 1999

23. Rosenblum B, Oldfield EH, Doppman JL, Di Chiro G: Spinal arteriovenous malformations: a comparison of dural arteriovenous fistulas and intradural AVM's in 81 patients. J Neurosurg 67:795-802, 1987

24. Schievink WI, Vishteh AG, McDougall CG, Spetzler RF: Intraoperative spinal angiography. J Neurosurg 90:48-51, 1999

25. Sinclair J, Chang SD, Gibbs IC, Adler JR Jr: Multisession CyberKnife radiosurgery for intramedullary spinal cord arteriovenous malformations. Neurosurgery 58:1081-1089, 2006

26. Spetzler RF, Detwiler PW, Riina HA, Porter RW: Modified classification of spinal cord vascular lesions. J Neurosurg 96:145-156, 2002

27. Spetzler RF, Zabramski JM, Flom RA: Management of juvenile spinal AVM's by embolization and operative excision. Case report. J Neurosurg 70:628-632, 1989 